\title{
Superconductivity in Carbide Compounds
}

\section{Takahiro Muranaka ${ }^{1}$ and Jun Akimitsu ${ }^{2 *}$}

${ }^{1}$ Department of Engineering Science, University of Electro-Communications, Tokyo, Japan

${ }^{2}$ Research Institute for Interdisciplinary Science, Okayama University, Okayama, Japan

\begin{abstract}
The discovery of superconductivity in $\mathrm{MgB}_{2}$ and B-doped diamond has stimulated the search for new superconducting materials in similar systems containing light elements. In the framework of BCS theory, high frequency phonons induced in a network of light elements can yield a higher superconducting transition temperature (Tc). It shows that light element superconductors provide one of the most promising paths to a room-temperature superconductor taking account of the relationship electronic state and bonding state.
\end{abstract}

Keywords: Superconductivity; Phonons; Sesqui-carbides

\section{Introduction}

The discovery of superconductivity in $\mathrm{MgB}_{2}$ [1] and B-doped diamond [2] has stimulated the search for new superconducting materials in similar systems containing light elements. In the framework of BCS theory [3], high frequency phonons induced in a network of light elements can yield a higher superconducting transition temperature $\left(T_{c}\right)$. These discoveries turned our attention towards new combinations of intermetallic compounds, and we discovered new superconductors in carbide systems, $\mathrm{Y}_{2} \mathrm{C}_{3}[4]$ and $\mathrm{B}$-doped $\mathrm{SiC}$ [5]. In this paper, we review these superconductors.

\section{Superconductivity in $\mathrm{Y}_{2} \mathrm{C}_{3}$}

Sesqui-carbides $\left(\mathrm{R}_{2} \mathrm{C}_{3}: \mathrm{R}=\mathrm{Y}, \mathrm{La}, \mathrm{Lu}\right)$ such as $\mathrm{Pu}_{2} \mathrm{C}_{3}$, which crystallize as bcc structures without an inversion center, are reported to exhibit superconductivity at relatively high temperatures for intermetallic compounds, with $T_{c}$ 's that depend on their carbon content [6-10]. The crystal structure of $\mathrm{Y}_{2} \mathrm{C}_{3}$ is shown in Figure 1. In this structure, $\mathrm{Y}$ atoms are aligned along the $<111>$ direction and $\mathrm{C}$ atoms form $\mathrm{C}-\mathrm{C}$ dimers.

In particular, Th substituted sesquicarbides of yttrium and lanthanum, $\left(\mathrm{R}_{2-x} \mathrm{Th}_{x}\right) \mathrm{C}_{3}$, have attracted attention because their $T_{c}$ 's are close to those of niobium-based A15-type superconductors. These materials showed superconductivity with a variable $T_{c}$, having a maximum at $17 \mathrm{~K}$. So, we attempted to synthesize the sesquicarbide material under higher temperature and pressure conditions. With a high temperature and pressure synthesis at 1473 1873 $\mathrm{K}$ and $4 \sim 5.5$ $\mathrm{GPa}$, using cubic-anvil-type equipment, we found that $\mathrm{Y}_{2} \mathrm{C}_{3}$ had a maximum $T_{c}$ of $18 \mathrm{~K}$, as shown in Figure 2.

From a theoretical point of view, the band structure of $\mathrm{Y}_{2} \mathrm{C}_{3}$ shows that the hybridization of $\mathrm{C}-\mathrm{C}$ dimer antibonding and the $\mathrm{Y}-4 d$ characteristics are dominant at the Fermi level $[11,12]$. The electronic structure of $\mathrm{YC}_{2}$ with $\mathrm{C}$ dimers suggests that the electronic structure could have substantial C-C antibonding character near the Fermi level [12]. It has been reported that low-frequency metal atom vibrations have the largest electron-phonon coupling in $\mathrm{Y}_{2} \mathrm{C}_{3}$, while the contribution of high-frequency C-C stretching vibrations is comparatively small [13].

However, the mechanism of superconductivity in $\mathrm{Y}_{2} \mathrm{C}_{3}$ has not been well understood because of the difficulty involved in synthesizing stable, single-phase $\mathrm{Y}_{2} \mathrm{C}_{3}$ in air. We established a technique for synthesizing high-purity samples, and prepared samples having various $T$ 's to investigate the mechanism of the variation of $T_{c}$ in this system $[14,15]$. As shown in Figure 3, the magnetic susceptibility of $\mathrm{Y}_{2} \mathrm{C}_{3}$ decreased significantly at each $T_{c}$ and the superconducting volume fraction of each $T_{\mathrm{c}}$ sample at lowest temperature in susceptibility measurements $(1.8 \mathrm{~K})$ was estimated to be approximately $40 \%$ in the field cooling process. The magnetization vs. magnetic field $(M-H)$ curves exhibit typical type-II superconducting behavior.

The electronic specific heat $\left(C_{\mathrm{e}}\right)$ of each sample (11K material, $13 \mathrm{~K}$ material, and $15 \mathrm{~K}$ material) is shown in Figure 4 . The total specific heat $(C)$ is expressed by following formula;

$$
C=C_{e l}+C_{p h}=\gamma T+\beta T^{3}+\delta T^{5}
$$

The $C_{\mathrm{d}}$ is obtained by subtracting the lattice part of the specific heat $\left(C_{\mathrm{ph}}\right)$ from the total specific heat $(C)$, which is measured at zero field and $8 \mathrm{~T}$, respectively. In this case, an applied field cannot completely suppress superconductivity, and $\gamma T$ in the $C_{\mathrm{el}}$ term provides a minor contribution. So we used the normal-state entropy formula;

$$
S_{n}=\gamma T+\frac{1}{3} \beta T^{3}+\frac{1}{5} \delta T^{5}
$$

Fordetermination of $\gamma$ and $\Theta_{D}$ (derived from $\beta=N(12 / 5) \pi^{4} R \Theta_{D}{ }^{(-3)}$, where $R=8.314 \mathrm{~J} /(\mathrm{molK})$ and $N=5)$ in an $S_{\mathrm{n}} / T$ vs. $T^{2}$ plot. This method is useful for a superconductor, in which superconductivity cannot be completely suppressed by an applied magnetic field [16]. The value of $\gamma$ and $\Theta_{D}$ of $Y_{2} C_{3}$ were calculated to be $4.7 \mathrm{~mJ} / \mathrm{molK}^{2}$ and $540 \mathrm{~K}$ for the $11 \mathrm{~K}$ material, $6.0 \mathrm{~mJ} / \mathrm{molK}^{2}$ and $530 \mathrm{~K}$ for the $13 \mathrm{~K}$ material, and $6.3 \mathrm{~mJ} /$ molK ${ }^{2}$ and $530 \mathrm{~K}$ for the $15 \mathrm{~K}$ material, respectively. The fitting below $T_{c}$ for each sample has revealed $\exp (-1 / T)$-dependence as predicted by BCS theory, rather than $T^{n}$-dependence as would an anisotropic superconductor. We estimated the superconducting gap parameters, $2 \Delta / k_{\mathrm{B}} T_{\mathrm{c}}$, to be $3.6,3.9$, and 4.1 for 11,13 , and $15 \mathrm{~K}$ materials, respectively. These facts suggest that the symmetry of the superconducting gap is an isotropic $s$-wave, and superconductivity in $\mathrm{Y}_{2} \mathrm{C}_{3}$ can be described as belonging to the strong coupling regime.

Figure 5 shows the temperature dependence of the specific heat of three samples under various magnetic fields. $T_{c}$ decreases with increasing applied field and the $\mu_{0} H_{c 2}(0)$ was determined from the midpoint temperature of the jump at several applied fields, shown in

*Corresponding author: Jun Akimitsu, Research Institute for Interdisciplinary Science, Okayama University, Okayama, Japan, Tel/Fax: 81-86-251-8632 E-mail: akimitsu@hiroshima-u.ac.jp

Received June 13, 2016; Accepted July 15, 2016; Published July 22, 2016

Citation: Muranaka T, Akimitsu J (2016) Superconductivity in Carbide Compounds Chem Sci J 7: 135. doi: 10.4172/2150-3494.1000135

Copyright: (C) 2016 Muranaka T, et al. This is an open-access article distributed under the terms of the Creative Commons Attribution License, which permits unrestricted use, distribution, and reproduction in any medium, provided the original author and source are credited. 


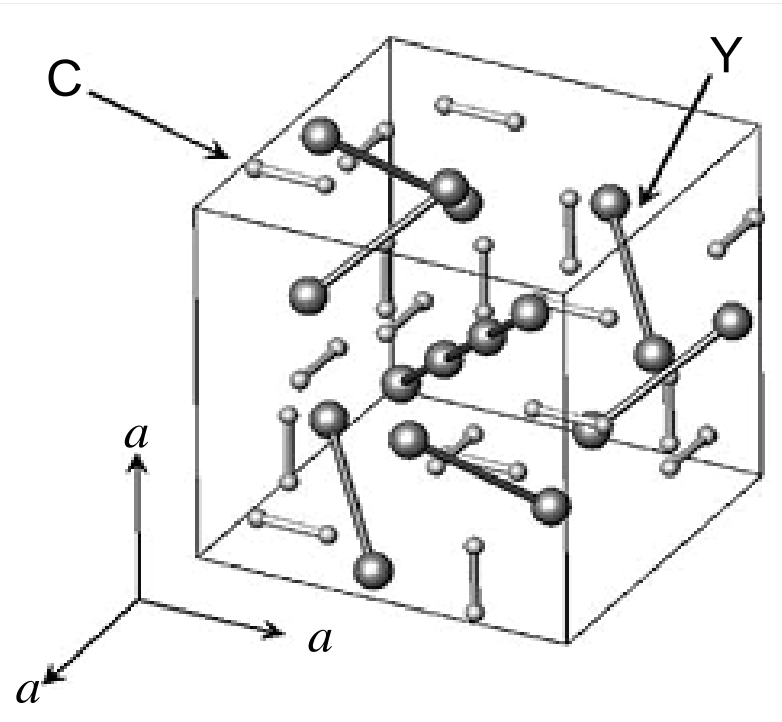

Figure 1: Crystal structure of $\mathrm{Y}_{2} \mathrm{C}_{3}$.

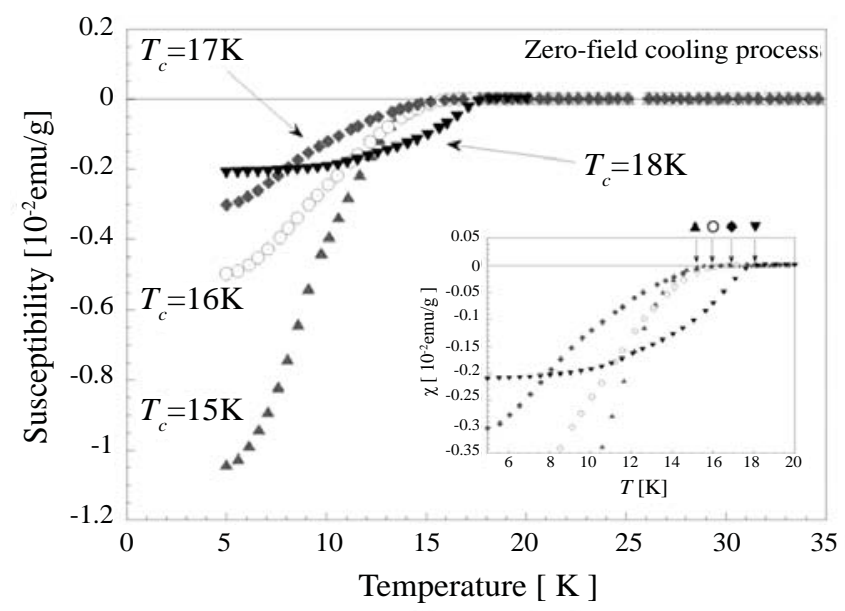

Figure 2: Temperature dependence of susceptibilities in $\mathrm{Y}_{2} \mathrm{C}_{3}$. The inset shows an expanded view near the $T_{\mathrm{c}}$ region.

Figure 6. The plots show a linear temperature dependence with the gradients $d H_{\mathrm{c} 2} / d T$, and $\mu_{0} H_{\mathrm{c} 2}(0)$ estimated to be about $22.7 \mathrm{~T}, 24.7 \mathrm{~T}$, and $26.8 \mathrm{~T}$, respectively, for the $11 \mathrm{~K}, 13 \mathrm{~K}$, and $15 \mathrm{~K}$ materials, from the relationship for type-II superconductors in the dirty limit;

$$
\mu_{0} H_{\mathrm{c} 2}(0) \cong 0.69 \times\left(-d H_{\mathrm{c} 2} / d T\right) \times T_{\mathrm{c}}
$$

and the coherence lengths, $\xi$, were determined to be 38,36 , and 35 $\AA$, respectively, for the $11 \mathrm{~K}, 13 \mathrm{~K}$, and $15 \mathrm{~K}$ materials from following formula;

$$
\mu_{0} H_{\mathrm{c} 2}(0) \sim \phi_{0} / \pi \xi^{2}
$$

Table 1 lists the superconducting parameters of three phases of $\mathrm{Y}_{2} \mathrm{C}_{3}$ with various $T_{c}$ 's. $\mathrm{Y}_{2} \mathrm{C}_{3}$ has a higher than $\mathrm{Nb}_{3} \mathrm{Sn}\left(T_{\mathrm{c}}=18 \mathrm{~K}, \Theta_{\mathrm{D}}=230 \mathrm{~K}\right)$ [17], being comparable to that of $\mathrm{YNi}_{2} \mathrm{~B}_{2} \mathrm{C}\left(T_{c}=14 \mathrm{~K}, \Theta_{\mathrm{D}}=533 \mathrm{~K}\right)$ [18]. From relatively high $\Theta_{\mathrm{D}}$, it is considered that the light element, Carbon, plays an important role in the superconductivity in $\mathrm{Y}_{2} \mathrm{C}_{3}$ and yields relatively high $T_{c}$. But $T_{c}$ in $\mathrm{Y}_{2} \mathrm{C}_{3}$ is not related to $\Theta_{\mathrm{D}}$ as tabulated in Table 1.
Therefore we focus on the relationship between $\gamma$ and $T_{c}$, the $T_{c}$ of $\mathrm{Y}_{2} \mathrm{C}_{3}$ increases as $\gamma$ increases. The $\gamma$ value is given by $\gamma=\pi^{2} k_{\mathrm{B}}{ }^{2} D\left(\epsilon_{F}\right)^{\mathrm{c} / 3}$, where $D\left(\epsilon_{F}\right)$ is the density of states at the Fermi level. In BCS theory, $T$ is given by $k_{\mathrm{B}} T_{\mathrm{c}} \cong 1.13 \hbar \omega_{\mathrm{D}} \exp \left(-1 / V_{0} D\left(\epsilon_{F}\right)\right)$, so it is considered that $T_{\mathrm{c}}$ in $\mathrm{Y}_{2} \mathrm{C}_{3}$ increases as $D\left(\epsilon_{F}\right)$ increases. However, the $\gamma$ value of $\mathrm{Y}_{2} \mathrm{C}_{3}$ is not very high in comparison with that of $\mathrm{Nb}_{3} \mathrm{Sn}$, where $\gamma=13 \mathrm{~mJ} / \mathrm{molK}^{2}$ [17]. So, we concluded that its high Debye temperature makes $T_{c}$ relatively high despite its small Sommerfeld coefficient.

Nakane et al. looked for the causes of different $T_{c}$ 's in $\mathrm{Y}_{2} \mathrm{C}_{3}$ structural properties, using neutron powder diffraction [19]. As they reported, high- $T_{c}(\sim 15 \mathrm{~K})$ and low- $T_{c}(\sim 11 \mathrm{~K})$ phases involved a small difference in C-C dimer distance, 1.298(4) $\AA$ for $15 \mathrm{~K}$ phase and 1.290 (4) $\AA$ for $11 \mathrm{~K}$ phase, while the lattice parameter was constant for all samples. Thus a change in $\mathrm{C}-\mathrm{C}$ dimer distance may induce a change of the electronic state of the $\mathrm{C}-\mathrm{C}$ dimer, resulting in an altered $T_{\mathrm{c}}$ in $\mathrm{Y}_{2} \mathrm{C}_{3}$.

Considering some other superconducting materials without an inversion center, $\mathrm{CePt}_{3} \mathrm{Si}$ and $\mathrm{Li}_{2} \mathrm{Pt}_{3} \mathrm{~B}$, their superconducting states are interesting because of the admixture of spin-singlet and spintriplet superconducting states that is induced by spin-orbit coupling $[20,21]$. Because $\mathrm{Y}_{2} \mathrm{C}_{3}$ does not have an inversion center in its crystal structure, the determination of the order parameter and the details of the superconducting gap structure are worth some attention.

In a ${ }^{13} \mathrm{C}$-NMR study of $\mathrm{Y}_{2} \mathrm{C}_{3}$ with a $T_{\mathrm{c}}=15.7 \mathrm{~K}$ at $H=0 \mathrm{~T}$, a clear decrease in ${ }^{13} \mathrm{C}$ Knight Shift and an increase in the full width at half maximum (FWHM) of ${ }^{13} \mathrm{C}-\mathrm{NMR}$ spectra are observed below $T_{\mathfrak{c}}$, as shown in Figure 7 [22]. It is suggested that the decrease of Knight Shift is due to a reduction of spin susceptibility associated with an onset of spin-singlet superconductivity in $\mathrm{Y}_{2} \mathrm{C}_{3}$, with the increase of FWHM possibly being due to an inhomogeneous distribution of vortex lattices.

\begin{tabular}{|c|c|c|c|}
\hline $\boldsymbol{T}_{\mathrm{c}}[\mathrm{K}]$ & 11.6 & 13.9 & 15.2 \\
\hline$\gamma\left[\mathbf{m} \mathbf{J} / \mathbf{m o l K}^{2}\right]$ & 4.7 & 6.0 & 6.3 \\
\hline$\Theta_{\mathrm{D}}[\mathrm{K}]$ & 540 & 530 & 530 \\
\hline$\mu_{0} \boldsymbol{H}_{\mathrm{c} 2}(\mathbf{0})[\mathrm{T}]$ & 22.7 & 24.7 & 26.8 \\
\hline $\mathbf{2} \Delta / \mathbf{k}_{\mathrm{B}} \boldsymbol{T}_{\mathrm{c}}$ & 3.6 & 3.9 & 4.1 \\
\hline$\xi[\AA]$ & 38 & 36 & 35 \\
\hline
\end{tabular}

Table 1: A summary of superconducting parameters of $\mathrm{Y}_{2} \mathrm{C}_{3}$.

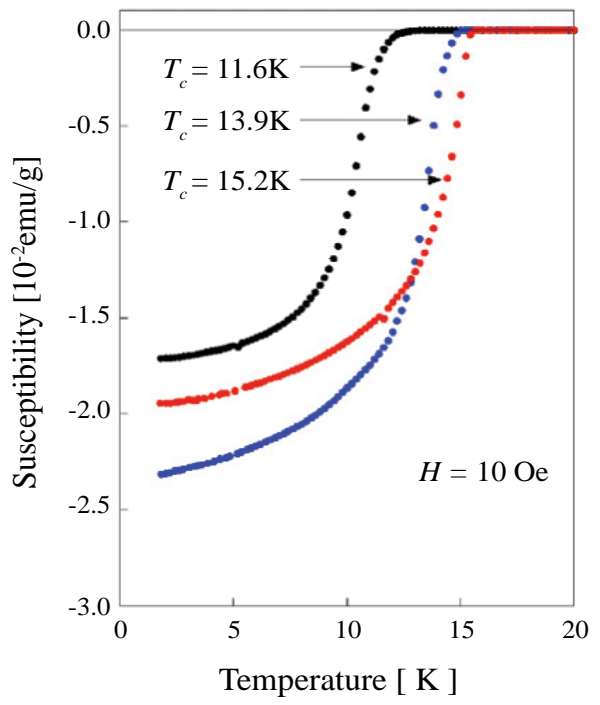

Figure 3: Temperature dependence of susceptibility of $\mathrm{Y}_{2} \mathrm{C}_{3}$ samples. 


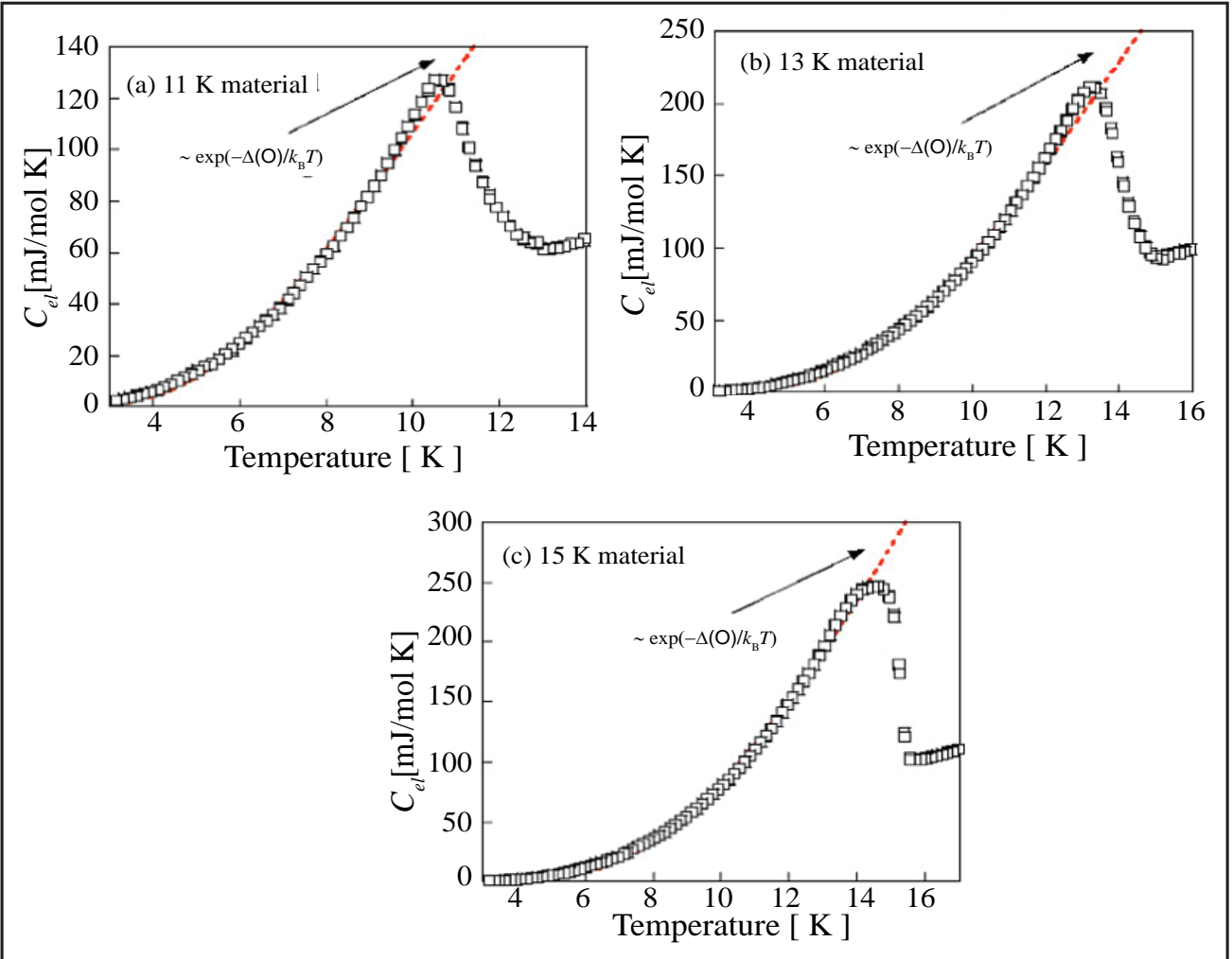

Figure 4: Temperature dependence of $\mathrm{C}_{\mathrm{el}}$ for (a) $11 \mathrm{~K}$, (b) $13 \mathrm{~K}$, and (c) $15 \mathrm{~K}$ materials. The dashed lines show exponential curves.

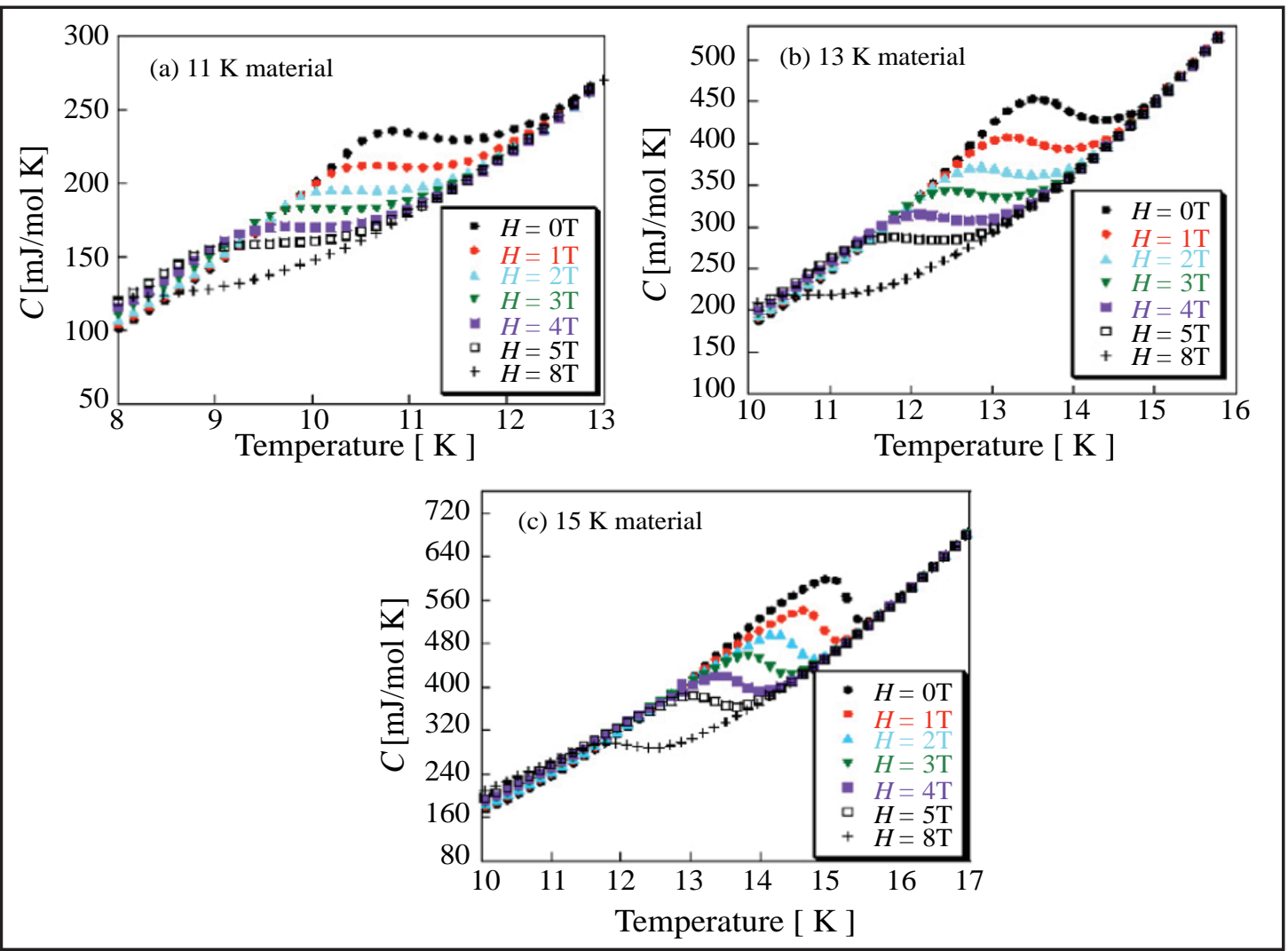

Figure 5: Temperature dependence of specific heat at various magnetic fields for (a) $11 \mathrm{~K}$, (b) $13 \mathrm{~K}$, and (c) $15 \mathrm{~K}$ materials. 


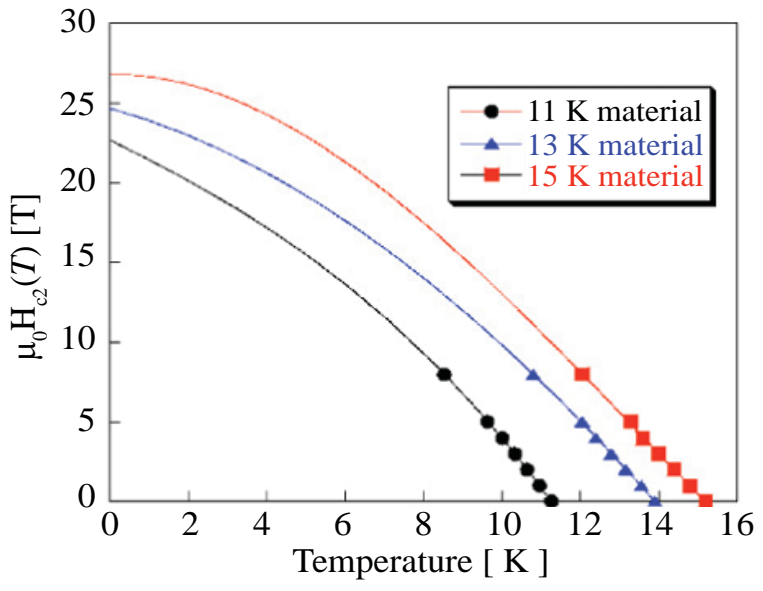

Figure 6: Upper critical fields, $\mu_{0} H_{c 2}(0)$, of $Y_{2} C_{3}$, determined by midpoint of jump of specific heat in magnetic fields. The solid lines are guides for the eye.

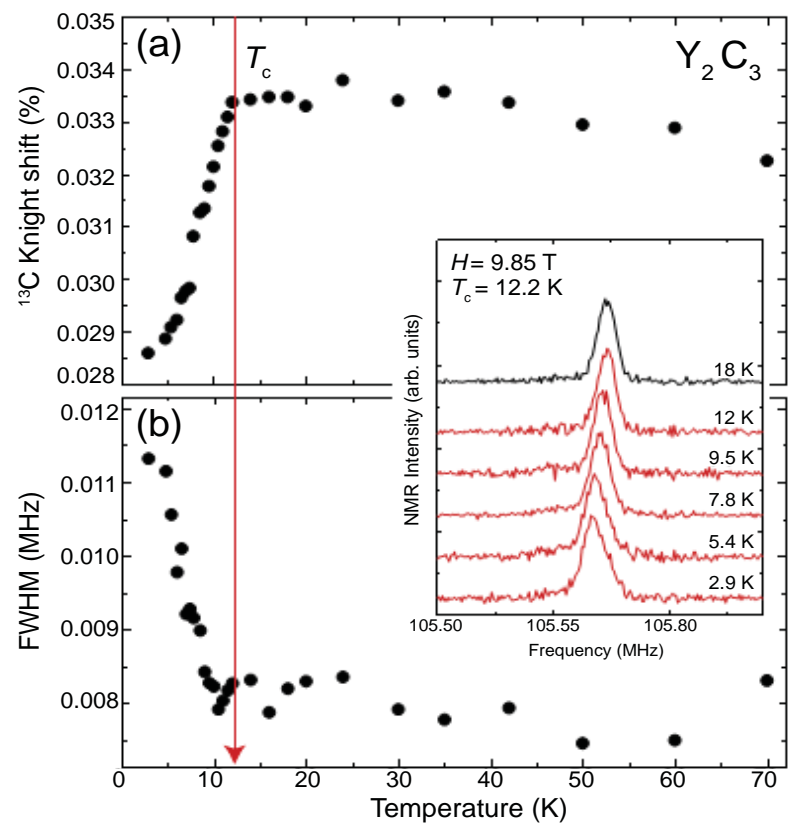

Figure 7: Temperature dependences of (a) ${ }^{13} \mathrm{C}$ Knight shift and (b) FWHM of ${ }^{13} \mathrm{C}$-NMR spectrum in $\mathrm{Y}_{2} \mathrm{C}_{3}$, with $T_{c}=12.2 \mathrm{~K}$ at $\mathrm{H}=9.85 \mathrm{~T}$. The inset shows the NMR spectra at several temperatures.

Figure 8 shows the temperature dependence of $1 / T_{1}$ in a magnetic field $(H=9.85 \mathrm{~T})$. In the normal state, the plots obey the law: $T_{1} T=$ Constant. As shown in the inset of Figure 8, a tiny coherence peak is observed in $\left(T_{1} T\right)_{\text {const }} /\left(T_{1} T\right)$ just below $T_{c}$ as in $\mathrm{MgB}_{2}$, indicating the opening of a full gap in the superconducting states of $\mathrm{Y}_{2} \mathrm{C}_{3}$. The temperature dependence of $1 / T_{1}$ below $T$ does not reveal a simple exponential term and seems to have small kink at around $5 \mathrm{~K}$.

Figure 9 shows the Arrhenius plot of $\left(T_{1} T\right) /\left(T_{1} T\right)_{\text {const }}$ vs. $T_{c} / T$, with $T_{c}=12.2 \mathrm{~K}$ at $H=9.85 \mathrm{~T}$ to help analyzing the details of the superconducting gap structure. The temperature dependence of $\left(T_{1} T\right) /$ $\left(T_{1} T\right)_{\text {const }}$ does not obey a simple power-law behavior such as $T^{2}$ dependence. It seems that a large full gap opens in the high-temperature region, and low-lying quasiparticle excitations in the low-temperature region are dominated by the presence of a small full gap. The large and small superconducting gaps, $2 \Delta / k_{\mathrm{B}} T_{\mathrm{c}}$, are estimated to be about 5 ( $T=5$ $\left.\mathrm{K} \sim T_{c}\right)$ and $2(T<5 \mathrm{~K})$, respectively. This behavior supporting multigap superconductivity in $\mathrm{Y}_{2} \mathrm{C}_{3}$ is not due to an extrinsic factor such as inhomogeneity of the samples, because $1 / T_{1}$ is uniquely determined by the simple exponential curve of nuclear magnetization as shown in the inset of Figure 9.

This multigap behavior in $\mathrm{Y}_{2} \mathrm{C}_{3}$ is also detected by $\mu \mathrm{SR}$ measurements $[23,24]$. In the $\mu S R$ study, muon spin relaxation rates of $\mathrm{Y}_{2} \mathrm{C}_{3}$ and $\mathrm{La}_{2} \mathrm{C}_{3}$ are reported. The crystal structure of $\mathrm{La}_{2} \mathrm{C}_{3}$ is a $\mathrm{Pu}_{2} \mathrm{C}_{3}$-type structure and its $T_{\mathrm{c}}$ 's are reported to be $6 \sim 13 \mathrm{~K}$ in different samples $[9,25,26]$. Therefore, an electronic structure similar to $\mathrm{Y}_{2} \mathrm{C}_{3}$ 's is expected for $\mathrm{La}_{2} \mathrm{C}_{3}$, making $\mathrm{La}_{2} \mathrm{C}_{3}$ is a good candidate for comparative study with $\mathrm{Y}_{2} \mathrm{C}_{3}$. The specific heat measurement of $\mathrm{La}_{2} \mathrm{C}_{3}$ is reported to suggest single-gap superconductivity [27].

Figure 10 shows the temperature dependence of the muon spin relaxation rate for $\mathrm{La}_{2} \mathrm{C}_{3}$ and $\mathrm{Y}_{2} \mathrm{C}_{3}$. It is noted that plots of $\mathrm{La}_{2} \mathrm{C}_{3}$ reveal a deviation from single-gap BCS-type superconducting behavior, though in the case of $\mathrm{Y}_{2} \mathrm{C}_{3}$, no strong anomaly is observed in the muon spin relaxation. However, the temperature dependence below $\sim 6 \mathrm{~K}\left(T / T_{c}<0.4\right)$ cannot be explained by a single-gap BCS picture. These temperature dependences can be understood from the double-gap structure in each compound by considering the Fermi surface of $\mathrm{Y}_{2} \mathrm{C}_{3}$ (three hole bands and one electron band) obtained by first-principles calculation [28].

Two superconducting gaps in $\mathrm{Y}_{2} \mathrm{C}_{3}$ and $\mathrm{La}_{2} \mathrm{C}_{3}$ can be realized by the differences in the density of states and Fermi velocities between hole and electron bands, so the temperature dependence of muon spin relaxation in each compound is affected by them. Taking the inter-band

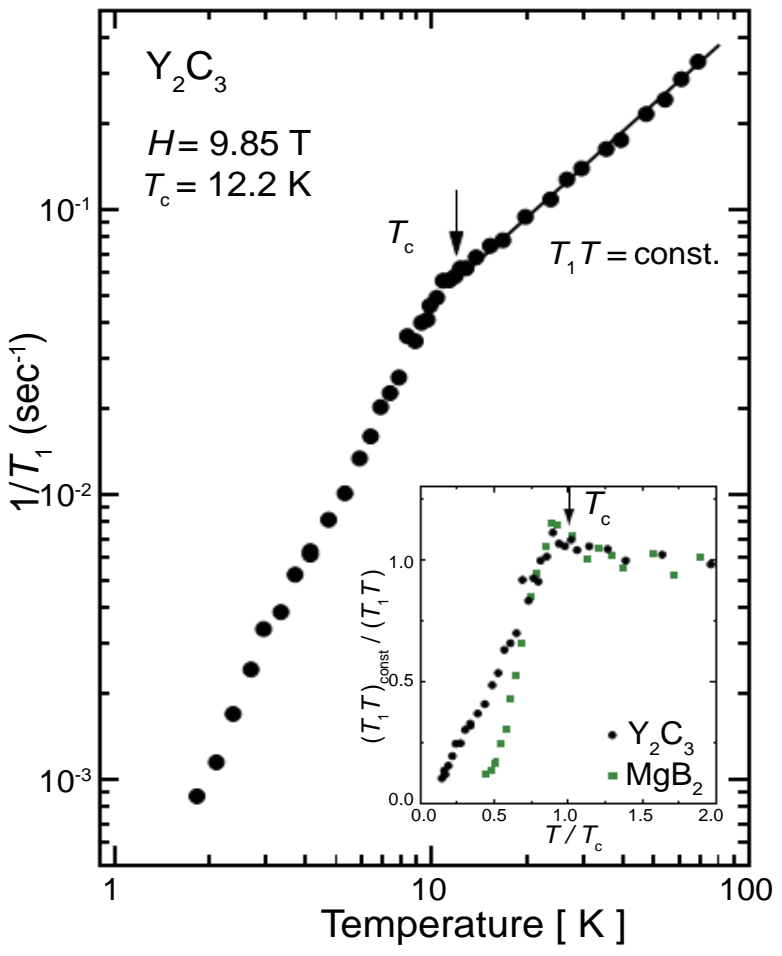

Figure 8: Temperature dependence of $1 / T_{1}$ for $Y_{2} C_{3}$, with $T_{c}=12.2 \mathrm{~K}$ at $H=9.85$ $\mathrm{T}$. The inset shows $\left(T_{1} T\right)_{1} /\left(T_{1} T\right)$ vs. $T / T_{\text {for }} \mathrm{Y}_{2} \mathrm{C}_{3}$ (solid circles) at $H=9.85 \mathrm{~T}$ and for $\mathrm{MgB}_{2}$ (solid squares) with $T_{\mathrm{c}}=29 \mathrm{~K}$ at $\mathrm{H}=4.4 \mathrm{~T}$ [23]. 


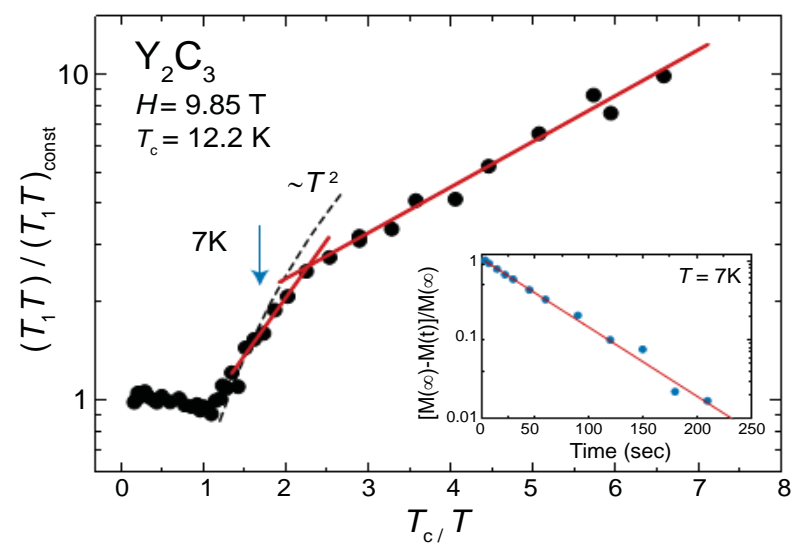

Figure 9: Arrhenius plot of $\left(T_{1} T\right) /\left(T_{1} T\right)_{\text {const }}$ vs. $T_{c} / T$, with $T_{c}=12.2 \mathrm{~K}$ at $H=9.85 \mathrm{~T}$ The inset shows a simple exponential recovery curve of nuclear magnetization.
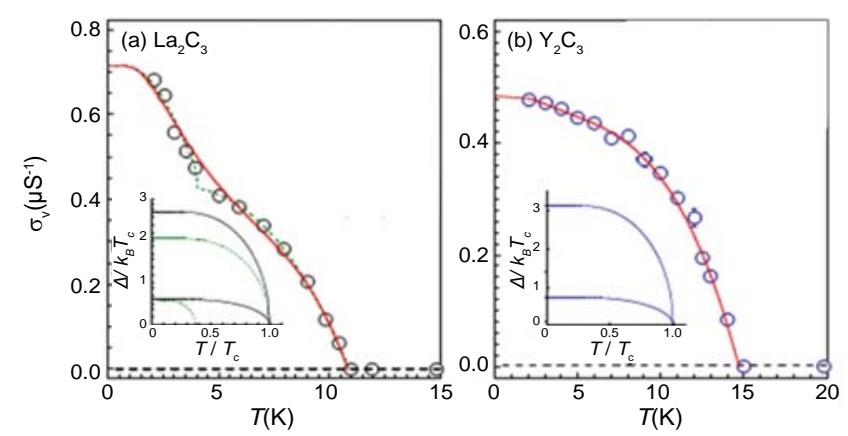

Figure 10: Temperature dependence of the muon spin relaxation rate for (a) $\mathrm{La}_{2} \mathrm{C}_{3}$ at $2.5 \mathrm{kOe}$ and $(\mathrm{b}) \mathrm{Y}_{2} \mathrm{C}_{3}$ at $5.0 \mathrm{kOe}$. Solid and dashed curves are fitting lines for the double-gap model. Insets show the order parameters $\Delta / k_{\mathrm{B}} T_{\mathrm{c}}$ for the respective cases.

coupling strength, $w$, between the two compounds into account, the results after analyzing the difference in the temperature dependence of muon spin relaxation between $\mathrm{Y}_{2} \mathrm{C}_{3}$ and $\mathrm{La}_{2} \mathrm{C}_{3}$ by the two-gap model are listed in Table 2.

The solid lines in Figure 10 show the best-fit lines using a phenomenological double-gap model with $s$-wave symmetry $[29,30]$. The obtained difference in the relative weight, $w$, between two gaps might be connected with inter-band coupling. For $\mathrm{La}_{2} \mathrm{C}_{3}$, a simple model assuming two independent superconducting gaps, shown with a dashed line, is also tested, and a slightly better fit is obtained than the result in Table 2 . This might suggest that the model may not necessarily be a good approximation for the case of weak inter-band coupling.

From the superconducting parameters of $\mathrm{Y}_{2} \mathrm{C}_{3}$ and $\mathrm{La}_{2} \mathrm{C}_{3}$ which are deduced from $\mu \mathrm{SR}$ measurements, the superconductivities in both compounds are described in the regime of strong electron-phonon coupling and $s$-wave symmetry, which is basically in good agreement with previous reports. However, in recent reports, the possibility of a nontrivial superconducting state in both compounds is pointed out. In the penetration depth, $\lambda(T)$, and the upper critical field, $\mu_{0} H_{c 2}(T)$, of $\mathrm{Y}_{2} \mathrm{C}_{3}$ using a tunnel-diode-based resonant oscillation technique, $\lambda(T)$ shows $T$-linear dependence at $T<T_{c}$ indicating the existence of a superconducting gap with line nodes, and the $\mu_{0} H_{c 2}(T)$ presents a weak upturn at low temperature with a rather high value of about 29
T, which exceeds the weak-coupling Pauli limit [31]. In ${ }^{139} \mathrm{La}$ and ${ }^{13} \mathrm{C}$ NMR of $\mathrm{La}_{2} \mathrm{C}_{3}{ }^{139} \mathrm{La}$ and ${ }^{13} \mathrm{C}$ NMR shifts in the superconducting state do not differ from the normal state, and the ${ }^{139} \mathrm{La}$ spin-lattice relaxation rate is strongly enhanced below $T_{c}$ [32]. These unconventional results can be attributed to the absence of inversion symmetry, which allows the possible mixture of spin-singlet and spin-triplet Cooper pairs in both compounds.

\section{Superconductivity in Boron-Doped Sic}

The superconductivity of doped semiconductors such as B-doped diamond in bulk [2] and films [33,34], and in B-doped $\mathrm{Si}$ [35] has stimulated renewed interest in the low-carrier-density superconductivity of doped semiconductors. In the case of B-doped diamond, experimental and theoretical research has sought to clarify whether its metallic nature arises from the holes at the top of the diamond valence band or from the boron impurity band formed above the valence band [36-47]. In particular, a higher- $T_{c}$ is suggested, where bonds transform into bands by carrier-doping to a semiconductor [48-50].

In terms of structural features and physical properties, we focused on $\mathrm{SiC}$, which has many stable polytypes including cubic zinc-blende, hexagonal and rhombohedral polytypes. As shown in Figure 11, in the cubic zinc-blende structure, labeled as $3 \mathrm{C}-\mathrm{SiC}$ or $\beta-\mathrm{SiC}, \mathrm{Si}$ and $\mathrm{C}$ occupy ordered sites in a diamond framework, and in hexagonal polytypes, $\mathrm{nH}-\mathrm{SiC}$, and rhombohedral polytypes, $\mathrm{nR}-\mathrm{SiC}$, generally referred to as a-SiC, $\mathrm{nSi}-\mathrm{C}$ bilayers consisting of $\mathrm{C}$ and $\mathrm{Si}$ layers are stacked in a primitive unit cell.

Undoped $\mathrm{SiC}$ is a wide-band-gap semiconductor with a band gap of $2 \sim 3 \mathrm{eV}$ depending on the crystal modification [51], and N, P, B, Al, etc. are lightly doped as donors or acceptors by ion implantation or thermal diffusion. When the dopant-induced carrier concentration increases, an insulator-to-metal transition occurs in semiconductors, and superconductivity has been induced in some semiconductors

\begin{tabular}{|c|c|c|}
\hline & $\mathrm{La}_{2} \mathrm{C}_{3}$ & $\mathbf{Y}_{2} \mathbf{C}_{3}$ \\
\hline Transverse field $(\mathrm{kOe})$ & 2.5 & 5.0 \\
\hline $\mathrm{T}_{\mathrm{c}}(\mathrm{K})$ & $10.9(1)$ & $14.7(2)$ \\
\hline$\sigma_{\mathrm{v}}(0)\left(\mu \mathrm{s}^{-1}\right)$ & $0.71(3)$ & $0.48(2)$ \\
\hline$\lambda(0)(\AA)$ & $3800(100)$ & $4600(100)$ \\
\hline $\mathrm{W}$ & $0.38(2)$ & $0.86(2)$ \\
\hline$\Delta_{1}(0)(\mathrm{meV})$ & $2.7(1)$ & $3.1(1)$ \\
\hline$\Delta_{2}(0)(\mathrm{meV})$ & $0.6(1)$ & $0.7(3)$ \\
\hline $2 \Delta_{1} / \mathrm{k}_{\mathrm{B}} T_{c}$ & $5.6(3)$ & $4.9(3)$ \\
\hline $2 \Delta_{2} / \mathrm{k}_{\mathrm{B}} T_{c}$ & $1.3(3)$ & $1.1(5)$ \\
\hline
\end{tabular}

Table 2: Superconducting parameters of $\mathrm{Y}_{2} \mathrm{C}_{3}$ and $\mathrm{La}_{2} \mathrm{C}_{3}$. (a)

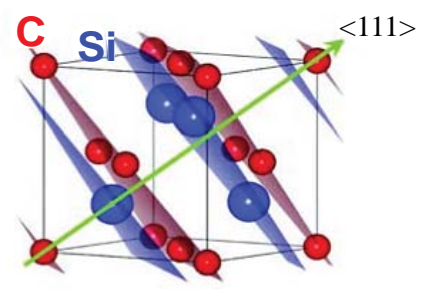

(b)

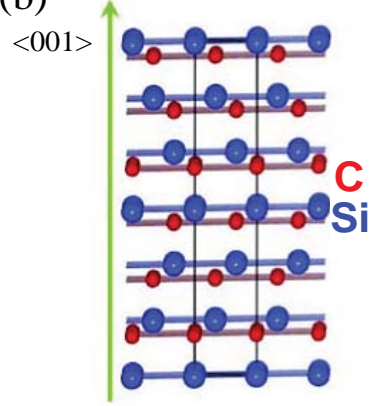

Figure 11: Unit cell of (a) cubic ${ }^{3} \mathrm{C}-\mathrm{SiC}$ and (b) hexagonal ${ }^{6} \mathrm{H}-\mathrm{SiC}$. 
[52-55], in accord with theoretical predictions [56,57]. In $\mathrm{SiC}$, the semiconductor-to-metal transition has been observed in n-type $\mathrm{N}$-doped $4 \mathrm{H}-\mathrm{SiC}$ with carrier concentrations above $10^{19} \mathrm{~cm}^{-3}$ without a superconducting transition [58].

In this situation, we succeeded in inducing type-I superconductivity in p-type boron-doped $3 \mathrm{C}$-SiC with a carrier concentration of 1.06-1.91 $\times 10^{21} \mathrm{~cm}^{-3}$ [5], and after this report we confirmed a superconducting transition in B-doped $6 \mathrm{H}-\mathrm{SiC}$ at a similar carrier concentration [59]. The question arises whether $\mathrm{SiC}$ exhibits superconductivity with different dopant elements. In fact, p-type $\mathrm{Al}$-doped $4 \mathrm{H}-\mathrm{SiC}$ with an $\mathrm{Al}$ concentration of $8.7 \times 10^{20} \mathrm{~cm}^{-3}$ showed metallic behaviors and a slight drop around $7 \mathrm{~K}$ in the temperature-dependence of sheet resistance [60]. We note that this drop may indicate the onset of a superconducting transition, but a superconducting transition has not been confirmed. However, we did induce type-II superconductivity in p-type Al-doped $3 \mathrm{C}-\mathrm{SiC}$ with a carrier concentration of $3.86-7.06 \times 10^{20} \mathrm{~cm}^{-3}[59]$.

From typical PXRD patterns of $\mathrm{B}$-doped $3 \mathrm{C}-\mathrm{SiC}$ and $6 \mathrm{H}-\mathrm{SiC}$, the main phases in each sample were indexed as cubic zinc-blende $3 \mathrm{C}-\mathrm{SiC}$, and hexagonal $6 \mathrm{H}-\mathrm{SiC}$ phases, respectively, as shown in Figure 12.

The refined lattice parameter of the major $3 \mathrm{C}-\mathrm{SiC}$ phase increased after sintering, though only by $\sim 0.1 \%$, from $4.3575(3) \AA$ to $4.3618(4)$ $\AA$, and the refined lattice parameter, $c$, of the major $6 \mathrm{H}-\mathrm{SiC}$ phase also increased after sintering by $\sim 0.2 \%$, from $15.06 \AA$ to $15.09 \AA$. However, the refined lattice parameter, $a$, of $6 \mathrm{H}-\mathrm{SiC}$ (in commercial $3.064 \AA$ ) did not change (within experimental accuracy). Because the atomic sizes of boron and carbon are comparable, but both are much smaller than silicon, the small changes in the lattice parameters suggest that boron substitutes at the carbon site in these samples. By means of the Hall effect at room temperature, the hole concentrations, $n$, were estimated to be $\sim 1.91 \times 10^{21} \mathrm{~cm}^{-3}$ for B-doped $3 \mathrm{C}-\mathrm{SiC}$ and $\sim 2.53 \times 10^{20} \mathrm{~cm}^{-3}$ for B-doped $6 \mathrm{H}$-SiC. The samples had much higher doping levels than those in previous reports [61-64]. The presence of liquid silicon in the sintering process may have helped boron diffusion and enhanced boron-substitution efficiency.

As shown in Figure 13, the magnetic susceptibility of B-doped $3 \mathrm{C}-\mathrm{SiC}$ and $6 \mathrm{H}-\mathrm{SiC}$ under a magnetic field of 1 Oe (zero field cooling process) significantly decreases at $\sim 1.4 \mathrm{~K}$, suggesting the occurrence of superconductivity with a superconducting volume fraction over $100 \%$ by the shielding effect.

Figure 14 shows magnetization vs. magnetic field $(M-H)$ curves of B-doped $3 \mathrm{C}-\mathrm{SiC}$ and $6 \mathrm{H}-\mathrm{SiC}$. These curves reveal type-I superconducting behavior. In both compounds, the onset field of magnetization shows a hysteresis about 30 Oe wide at the lowest temperature. Hysteresis during increasing and decreasing fields suggests that a 1st order transition under a finite magnetic field is occurring in both compounds, supporting type-I superconductivity. From the $M-H$ curves, the critical field, $H_{\mathrm{c}}$, is estimated to be about 100 Oe.

As shown in Figure 15, the electrical resistivity in B-doped 3C-SiC:B and $6 \mathrm{H}-\mathrm{SiC}$ reveals metallic conductivity, reflecting the high carrierdoping level with residual resistivity ratios, $R R R\left(\rho_{300 \mathrm{~K}} / \rho_{5 \mathrm{~K}}\right)$, of 11.4 and 4.7 , respectively. B-doped $3 \mathrm{C}-\mathrm{SiC}$ exhibits a much smaller resistivity, almost $T$-linear, but $\mathrm{B}$-doped $6 \mathrm{H}$-SiC exhibits a broad feature at around $150 \mathrm{~K}$ suggesting the weak localization of carriers or a contribution from non-metallic grain boundaries. The inset of Figure 15 shows an expanded view of the low-temperature data. The resistivities exhibit sharp drops at $1.5 \mathrm{~K}$ (B-doped 3C-SiC) and 1.4 K (B-doped 6H-SiC), corresponding to the $T_{\mathrm{c}}$ 's observed from the susceptibility.

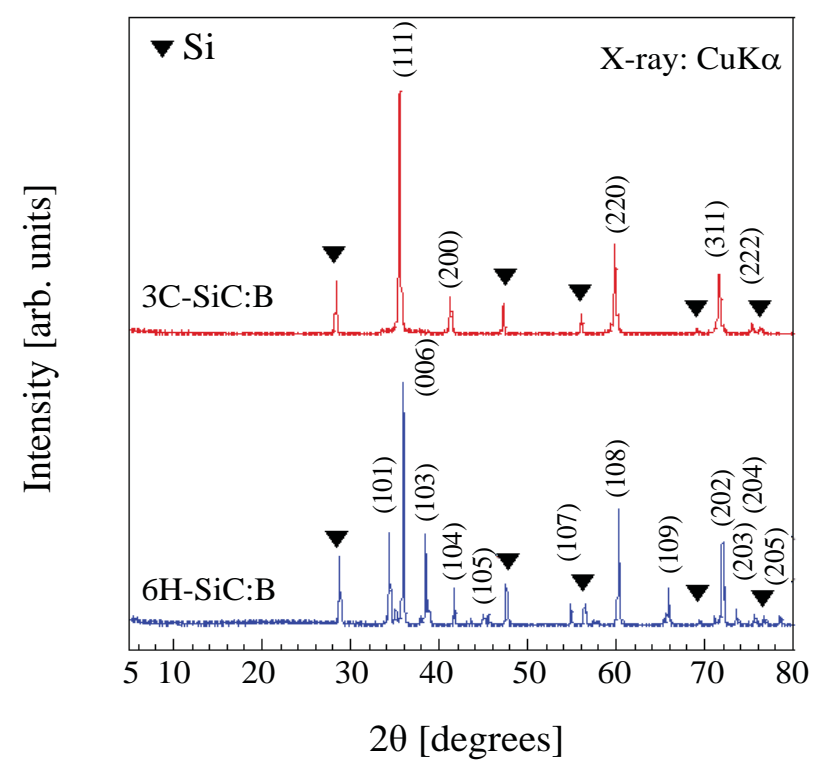

Figure 12: Powder X-ray diffraction patterns in B-doped 3C-SiC (3C-SiC:B) and $\mathrm{B}-$ doped $6 \mathrm{H}-\mathrm{SiC}(6 \mathrm{H}-\mathrm{SiC}: \mathrm{B})$.

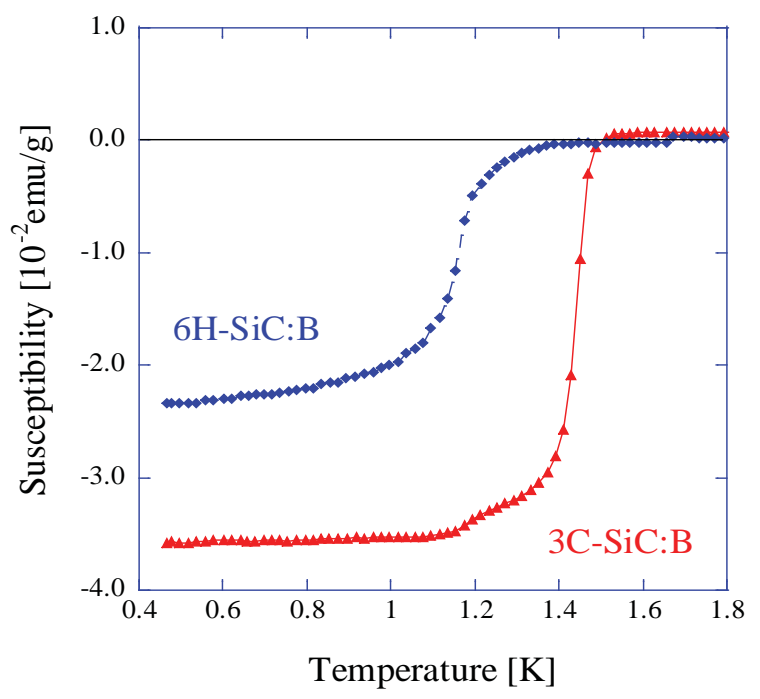

Figure 13: Temperature dependence of susceptibility in B-doped 3C-SiC (3C-SiC:B) and B-doped 6H-SiC (6H-SiC:B).

To determine the phase diagram in the magnetic field-temperature $(H-T)$ plane for both samples, the resistivities were measured by varying the temperature at different magnetic fields ( $T$-scan shown in Figure $16)$, and varying the magnetic fields at different temperatures ( $H$-scan shown in Figure 17). In the $T$-scan, only one transition was observed at $T_{c}$ at zero field, while a large super cooling effect was observed in both $\mathrm{SiC}$ samples in finite fields. In the $H$-scan, hysteresis was also observed under 130 Oe in B-doped 3C-SiC and 100 Oe in B-doped 6H-SiC. The (i) in-field hysteresis, (ii) absence of hysteresis in a zero field, and (iii) very small value of the critical field, give strong evidence for type-I superconductivity in both $\mathrm{SiC}$ polytypes.

The $H-T$ phase diagram determined from the resistivity data ( $T$-scan and $H$-scan) is shown in Figure 18. Applying the conventional 

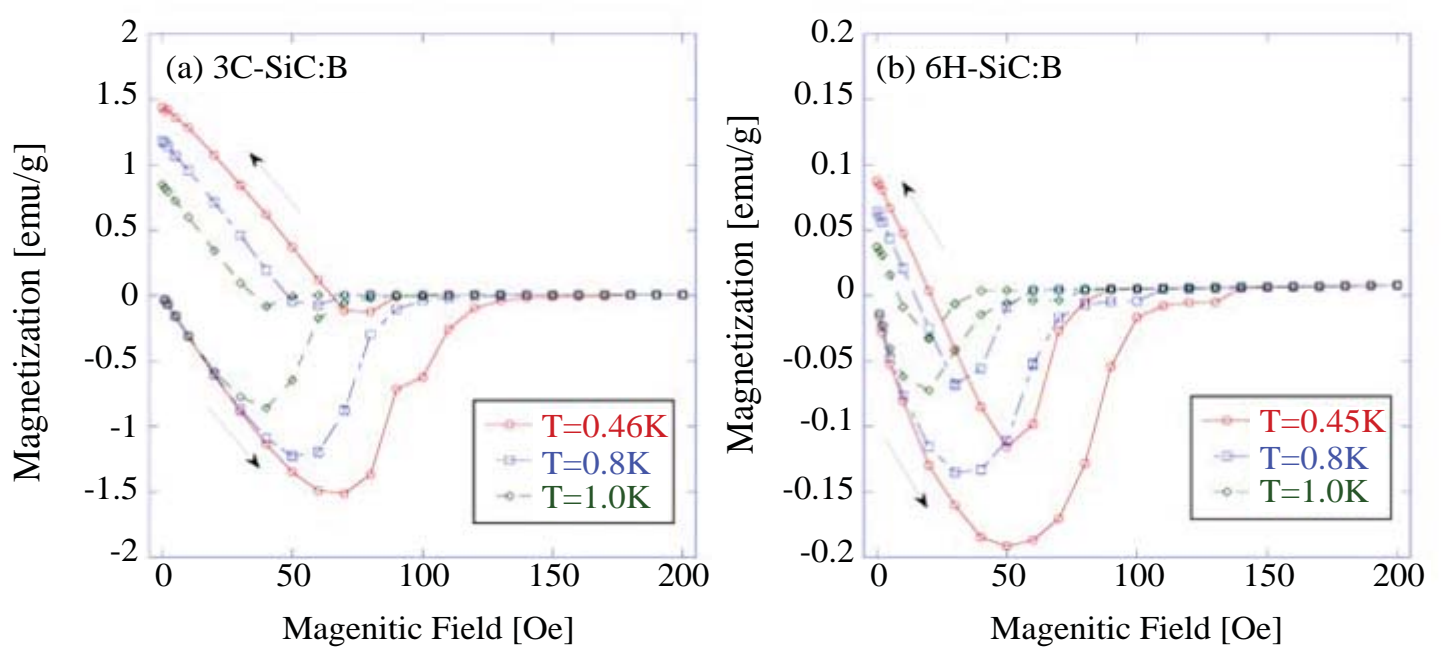

Figure 14: Magnetization versus magnetic field curves in (a) B-doped 3C-SiC (3C-SiC:B) and (b) B-doped 6H-SiC $(6 \mathrm{H}-\mathrm{SiC}: \mathrm{B})$.

formula $H_{c}(T)=H_{c}(0)\left[1-\left(T / T_{c}(0)\right)^{\alpha}\right]$, the thermodynamic critical field, $H_{c}(T)$, is estimated to be $132 \pm 3$ Oe with $\alpha \sim 2.0$ for B-doped 3C-SiC and $125 \pm 5$ Oe with $\alpha \sim 1.6$ for B-doped $6 \mathrm{H}-\mathrm{SiC}$ in the warming plots. The same procedure applied to the cooling plots yields $\alpha \sim 1.6$ in both $\mathrm{SiC}$ polytypes. This transition is identified as the upper limit of the intrinsic super cooling limit. The corresponding transition fields are denoted as $H_{\text {sc }}$ (the subscript "sc" stands for super cooling) with an estimated $H_{\mathrm{sc}}(0)=102 \pm 6$ Oe for B-doped $3 \mathrm{C}-\mathrm{SiC}$ and $94 \pm 3$ Oe for B-doped $6 \mathrm{H}-\mathrm{SiC}$, respectively.

Applying the Ginzburg-Landau (GL) theory of type-I superconductivity to these data, one can estimate an upper limit of the GL parameter $\kappa$ from the difference of the critical fields obtained by a field-cooling run and a subsequent warming run $[65,66]$ : $\kappa(0) \leq H_{s c}(0) /\left(1.695 \times \sqrt{2} H_{c}(0)\right)$. This formula yields $\kappa \sim 0.32$ for B-doped $3 \mathrm{C}$ - $\mathrm{SiC}$ and 0.31 for $\mathrm{B}$-doped $6 \mathrm{H}-\mathrm{SiC}$, in agreement with the analysis of the Hall effect and the specific heat data $[67,68]$. This supports the type-I nature of superconductivity in B-doped $\mathrm{SiC}$. Note that the value of $\kappa$ is below 0.41 , which is required in a model based on super cooling instead of superheating $[66,69,70]$.

Table 3 lists basic normal-state parameters: Fermi wave number $k_{\mathrm{F}}$, effective mass $m^{*}$, Fermi velocity $v_{\mathrm{F}}$, mean free path $l$; as well as superconducting state parameters: penetration depth $\lambda$, coherence length $\xi$ and Ginzburg-Landau parameter $\kappa_{\mathrm{GL}}$ deduced from $T$-scan and $H$-scan in resistivity, Hall effect, and specific heat $[67,68]$.

For comparison, the previously reported parameters for B-doped diamond $(\mathrm{C}: \mathrm{B})$ and $\mathrm{B}$-doped $\mathrm{Si}(\mathrm{Si}: \mathrm{B})$ are added. The coherence lengths of $\mathrm{B}$-doped $3 \mathrm{C}-\mathrm{SiC}$ and $6 \mathrm{H}-\mathrm{SiC}$ are compared with $\mathrm{B}$-doped diamond and B-doped Si. Type-I superconductivity in B-doped SiC originates in these long coherence lengths.

However, it is not clear why $\mathrm{SiC}: \mathrm{B}$ reveals type-I superconductivity in spite of the dirty limit $(l<<\xi)$. From SEM images of B-doped SiC samples (not shown in this paper), the maximum crystal grain size is about $5 \mu \mathrm{m}$, and in higher B-content samples (higher starting ratio), the crystal grain size tends to grow much larger. Crystal grain size growth is enhanced by adding $\mathrm{Si}$ and $\mathrm{B}$ during the synthesis process.

However, $T_{\mathrm{c}}$ in superconducting B-doped SiC samples does not change with the B-nominal composition. It is considered that the

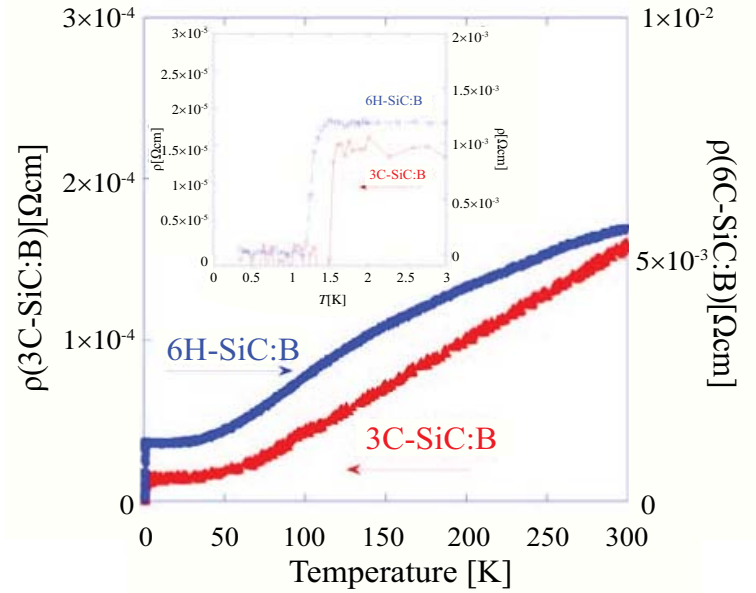

Figure 15: Temperature dependence of resistivity in B-doped 3C-SiC (3C-SiC:B) and $\mathrm{B}$-doped $6 \mathrm{H}-\mathrm{SiC}(6 \mathrm{H}-\mathrm{SiC}: \mathrm{B})$. The inset magnifies the region near $\mathrm{T}_{\mathrm{c}}$.

\begin{tabular}{|c|c|c|c|c|}
\hline & 3C-SiC:B & 6 H-SiC:B & C:B & Si:B \\
\hline$n\left[\mathrm{~cm}^{-3}\right]$ & $1.91 \times 10^{21}$ & $2.53 \times{ }^{10} 20$ & $1.80 \times 10^{21}$ & $2.80 \times 10^{21}$ \\
\hline $\mathrm{Y}_{\mathrm{n}}\left[\mathrm{mJ} / \mathrm{molK}^{2}\right]$ & 0.294 & 0.35 & 0.113 & - \\
\hline$\rho_{0}[\mathrm{~m} \Omega \mathrm{cm}]$ & 0.06 & 1.19 & 2.5 & 0.13 \\
\hline$R R R$ & 11.4 & 4.7 & 0.9 & 1.2 \\
\hline$T_{\mathrm{c}}[\mathrm{K}]$ & 1.5 & 1.4 & 4.5 & 0.35 \\
\hline$H_{\mathrm{c}}(0)[\mathrm{Oe}]$ & 132 & 125 & - & - \\
\hline$H_{\mathrm{sc}}(0)[\mathrm{Oe}]$ & 102 & 94 & - & - \\
\hline$H_{\mathrm{c} 2}(0)[\mathrm{Oe}]$ & - & - & $4.2 \times 10^{4}$ & $4 \times 10^{3}$ \\
\hline$k_{\mathrm{F}}\left[\mathrm{nm}{ }^{-1}\right]$ & 3.8 & 2.0 & 3.8 & - \\
\hline$m^{*}\left[m_{\mathrm{el}}\right]$ & 1.2 & 1.9 & 1.7 & - \\
\hline$v_{\mathrm{F}}[\mathrm{m} / \mathrm{s}]$ & $3.8 \times 10^{5}$ & $1.1 \times 10^{5}$ & - & - \\
\hline$I[\mathrm{~nm}]$ & 14 & 2.8 & 0.34 & - \\
\hline$\xi(0)[\mathrm{nm}]$ & 360 & 112 & $80(9)$ & $(20)$ \\
\hline$\lambda(0)[\mathrm{nm}]$ & 130 & 140 & 160 & - \\
\hline $\mathrm{K}_{\mathrm{GL}}$ & 0.32 & 0.31 & $2(18)$ & - \\
\hline
\end{tabular}

Table 3: Parameters in normal and superconducting states of B-doped 3C-SiC B-doped $6 \mathrm{H}-\mathrm{SiC}[5,59,67,68]$, B-doped diamond $[2,36]$ and B-doped Si [35]. 

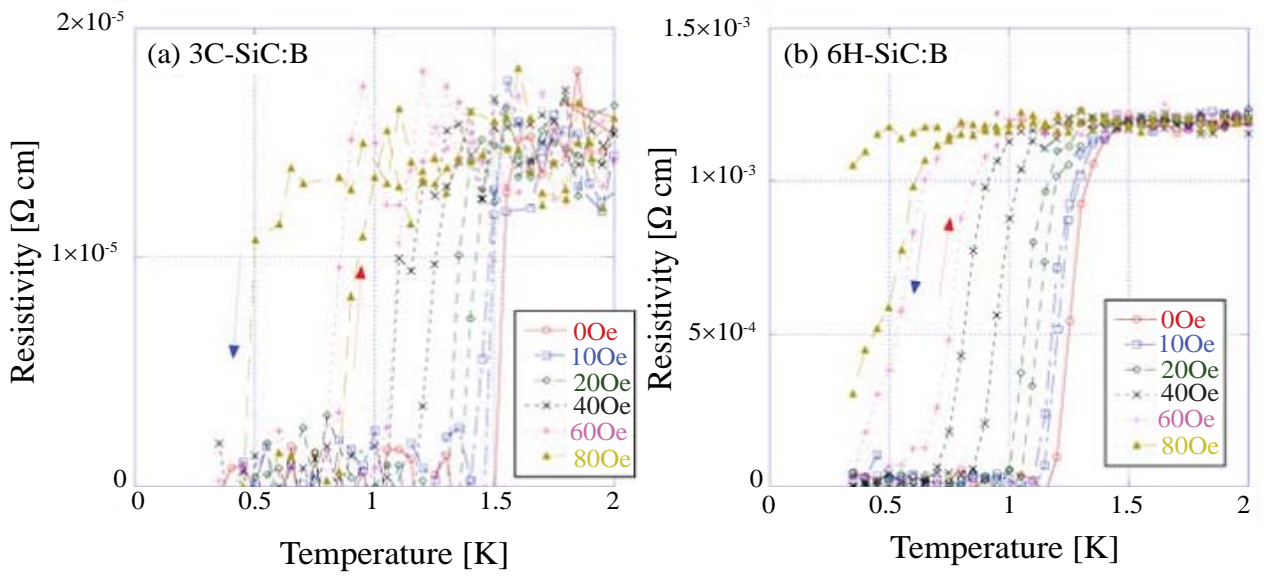

Figure 16: Temperature dependence of resistivity under magnetic fields ( $T$-scan) in (a) B-doped 3C-SiC (3C-SiC:B) and (b) B-doped 6H-SiC (6H-SiC:B).
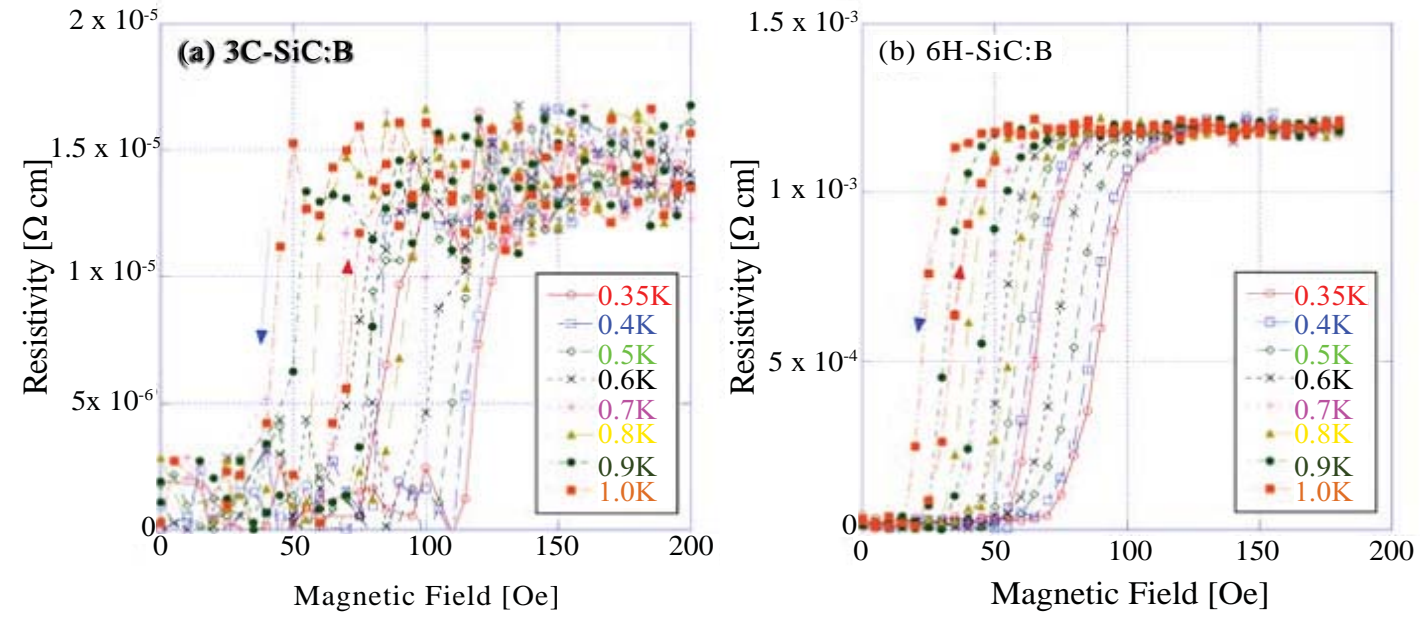

Figure 17: Magnetic field dependence of resistivity $(\mathrm{H}$-scan) in (a) B-doped 3C-SiC (3C-SiC:B) and (b) B-doped 6H-SiC (6H-SiC:B)
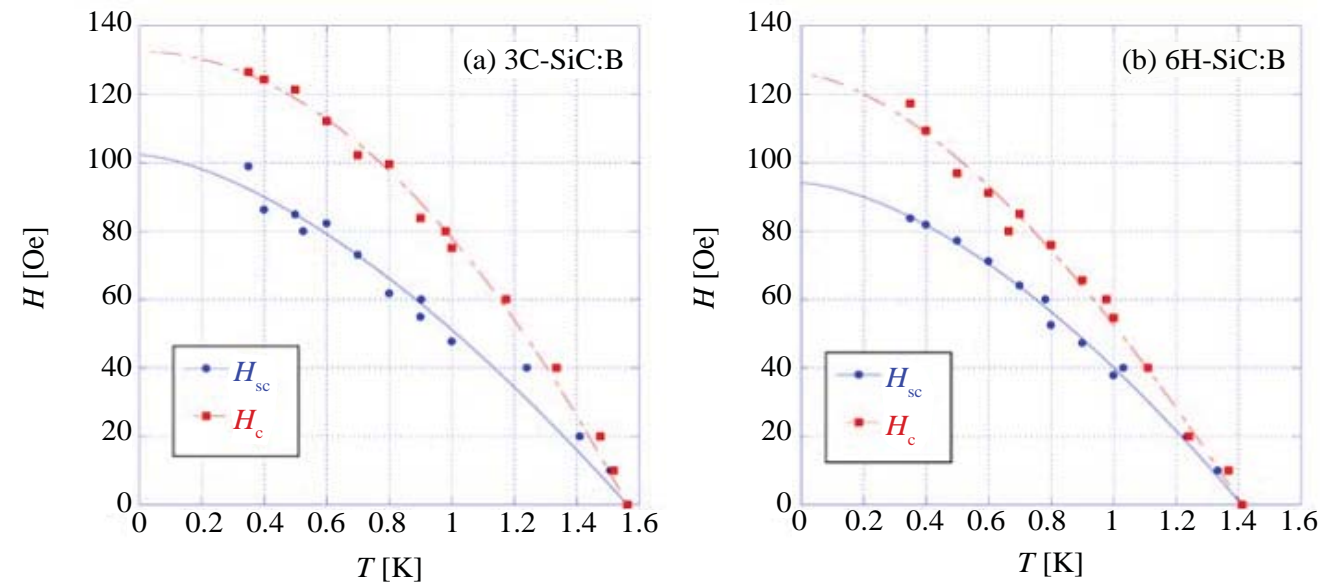

Figure 18: $\mathrm{H}$-T phase diagram for (a) B-doped 3C-SiC (3C-SiC:B) and (b) B-doped 6H-SiC (6H-SiC:B), determined from the onset of superconductivity in T-scan and $\mathrm{H}$-scan of resistivity. 
B-doping level in $\mathrm{B}$-doped $\mathrm{SiC}$ has already reached the limiting level (a certain constant $\mathrm{B} / \mathrm{C}$ ratio) in a solid state reaction. As a result, $T$ does not change. Moreover, the mean free path $l$ in $\mathrm{B}$-doped $\mathrm{SiC}$ samples is reduced by grain boundary effects or un-reacted starting powder. Thus the mean free path $l$ in B-doped $\mathrm{SiC}$ can be extended up to the clean limit $(l>>\xi)$ in a high quality sample.

\section{Conclusion}

We have reviewed superconductivity in carbide compounds, whose $T$ 's are unfortunately limited to the $10 \mathrm{~K} \sim 20 \mathrm{~K}$ range. During the process in the developments of these superconductors, we focused on the high frequency phonon which was induced by light element. The maximum $T_{c}$ in sesqui-carbides and wide band-gap semiconductors are $18 \mathrm{~K}$ and $11 \mathrm{~K}$, respectively, at this stage. So, other routes have to be sought for development of new high- $T$ superconductor. Recently, much attention has been paid to the new superconductor $\mathrm{H}_{3} \mathrm{~S}$ ( $T$ $\simeq 200 \mathrm{~K})$ under ultra-high pressure $(200 \simeq \mathrm{GPa})$, which can be described by the BCS theory [71]. This probably shows that light element superconductors provide one of the most promising paths to a room-temperature superconductor taking account of the relationship electronic state and bonding state.

\section{Acknowledgements}

This work is supported by Grant-in-Aid from Ministry of Education, Culture, Sports, Science and Technology (MEXT) under No. 25000003, 26247057, and by JSPS KAKENHI Grant Number $15 \mathrm{H} 05886$ and partially by the Program for Advancing Strategic International Networks to Accelerate the Circulation of Talented Researchers from Japan Society for the Promotion of Science.

\section{References}

1. Nagamatsu J, Nakagawa N, Muranaka T, Zenitani Y, Akimitsu J (2001) Superconductivity at $39 \mathrm{~K}$ in magnesium diboride. Nature 410: 63-64.

2. Ekimov EA, Sidorov VA, Bauer ED, Mel'nik NN, Curro NJ, et al. (2004) Superconductivity in diamond. Nature 428: 542-545.

3. Bardeen J, Cooper LN, Schrieffer JR (1957) Theory of Superconductivity. Phys Rev 108: 1175-1204

4. Amano G, Akutagawa S, Muranaka T, Zenitani Y, Akimitsu J (2004) Superconductivity at $18 \mathrm{~K}$ in Yttrium Sesquicarbide System, $\mathrm{Y}_{2} \mathrm{C}_{3}$. J Phys Soc Jpn 73: 530-532.

5. Ren ZA, Kato J, Muranaka T, Akimitsu J, Kriener M, et al. (2007) Superconductivity in Boron-doped SiC. J Phys Soc Jpn 76: 10370.

6. Giorgi AL (1985) Superconductivity in the Lanthanum Carbon System. High Temp Sci 19: 127-131.

7. Krupka MC, Giorgi AL, Krikorian NH, Szklarz EG (1969) High pressure synthesis and superconducting properties of yttrium sesquicarbide. J Less Common Met 17: 91-98.

8. Krupka MC, Giorgi AL, Krikorian NH, Szklarz EG (1969) High-pressure synthesis of yttrium-thorium sesquicarbide: a new high-temperature superconductor. $\mathrm{J}$ Less Common Met 19: 113-119.

9. Simon A, Gulden T (2004) $\mathrm{La}_{2} \mathrm{C}_{3}$ und seine Reaktion mit Wasserstoff. Z Anorg Allg Chem 630: 2191-2198.

10. Poople CP, Farach HA (2000) Tabulations and Correlations of Transition Temperatures of Classical Superconductors. J Supercond 13: 47-60.

11. Shein IR, Ivanovski AL (2004) Electronic properties of the novel 18-K superconducting $\mathrm{Y}_{2} \mathrm{C}_{3}$ as compared with $4-\mathrm{K} Y C 2$ from first principles calculations. Solid State Commun 131: 223-227.

12. Gulden Th, Henn RW, Jepsen O, Kremer RK, Schnelle W, et al. (1997) Electronic properties of the yttriumdicarbide superconductors $\mathrm{YC}_{2}, \mathrm{Y}_{1-\mathrm{x}} \mathrm{Th}_{\mathrm{x}} \mathrm{C}_{2}$, $\mathrm{Y}_{1-x} \mathrm{Ca}_{x} \mathrm{C}_{2}(0<x<\sim 0.3)$. Phys Rev B 56: 9021-9029.

13. Singh DJ, Mazin II (2004) Electronic structure and electron-phonon coupling in the $18 \mathrm{~K}$ superconductor $\mathrm{Y}_{2} \mathrm{C}_{3}$. Phys Rev B 70: 052504.

14. Akutagawa $S$, Akimitsu $J(2006)$ Superconductivity in $Y_{2} C_{3}$ with medium $T_{c}$. Sci Technol Adv Mater 7: 2-5.
15. Akutagawa $S$, Akimitsu $J$ (2007) Superconductivity of $Y_{2} C_{3}$ Investigated by Specific Heat Measurement. J Phys Soc Jpn 76: 024713

16. Guritanu V, Goldacker W, Bouquet F, Wang Y, Lortz R, et al. (2004) Specific heat of $\mathrm{Nb}_{3} \mathrm{Sn}$ : The case for a second energy gap. Phys Rev B 70: 184526.

17. Junod A, Wang Y, Bouquet F, Toulemonde P (2002) Studies of High Temperature Superconductors. Narlikar AV (Ed.) Nova Science Publishers, Commack, NY, USA) 38: 179 .

18. Huang CL, Lin JY, Sun CP, Lee TK, Kim JD, et al. (2006) Comparative analysis of specific heat of $\mathrm{YNi}_{2} \mathrm{~B}_{2} \mathrm{C}$ using nodal and two-gap models. Phys Rev $\mathrm{B} 73$ 012502

19. Nakane T, Naka T, Mochiku T, Kito H, Harjo S, et al. (2006) Origin of the difference between the high and low-T c phases in the yttrium sesquicarbide system. Sci Technol Adv Mater 7: S99-S103.

20. Yogi M, Kitaoka Y, Hashimoto S, Yasuda T, Settai R, et al. (2004) Evidence for a Novel State of Superconductivity in Noncentrosymmetric $\mathrm{CePt}_{3} \mathrm{Si}: \mathrm{A}{ }^{195} \mathrm{Pt}-\mathrm{NMR}$ Study. Phys Rev Lett 93: 027003.

21. Yuan HQ, Agterberg DF, Hayashi N, Badica P, Vandervelde D, et al. (2006) S-Wave Spin-Triplet Order in Superconductors without Inversion Symmetry: $\mathrm{Li}_{2} \mathrm{Pd}_{3} \mathrm{~B}$ and $\mathrm{Li}_{2} \mathrm{Pt}_{3} \mathrm{~B}$. Phys Rev Lett 97: 017006.

22. Harada A, Akutagawa S, Miyamichi $Y$, Mukuda H, Kitaoka $Y$, et al. (2007) Multigap Superconductivity in $\mathrm{Y}_{2} \mathrm{C}_{3}$ : $\mathrm{A}{ }^{13} \mathrm{C}-\mathrm{NMR}$ Study. J Phys Soc Jpn 76: 023704

23. Kotegawa H, Ishida K, Kitaoka Y, Muranaka T, Akimitsu J (2001) Evidence for Strong-Coupling s-Wave Superconductivity in $\mathrm{MgB}_{2}:{ }^{11} \mathrm{~B}$ NMR Study. Phys Rev Lett 87: 127001.

24. Kuroiwa S, Saura Y, Akimitsu J, Hiraishi M, Miyazaki M, et al. (2008) Multigap Superconductivity in Sesquicarbides $\mathrm{La}_{2} \mathrm{C}_{3}$ and $\mathrm{Y}_{2} \mathrm{C}_{3}$. Phys Rev Lett 100: 097002.

25. Giorgi AL, Szklarz FG, Krupka MC, Krikorian NH (1969) Occurrence of superconductivity in lanthanum sesquicarbide. J Less Common Met 17: 121-123.

26. Kim JS, Kremer RK, Jepsen O, Simon A (2006) Electronic and superconducting properties of the binary carbide $\mathrm{La}_{2} \mathrm{C}_{3}$. Curr Appl Phys 6: 897-902.

27. Kim JS, Xie WH, Kremer RK, Babizhetskyy V, Jepsen O, et al. (2007) Strong electron-phonon coupling in the rare-earth carbide superconductor $\mathrm{La}_{2} \mathrm{C}_{3}$. Phys Rev B 76: 014516.

28. Nishikayama $Y$, Shishido T, Oguchi T (2007) Electronic Properties of $\mathrm{Y}_{2} \mathrm{C}_{3}$ by First-Principles Calculations. J Phys Soc Jpn 76: 064714

29. Bouquet F, Wang Y, Fisher RA, Hinks DG, Jorgensen JD, et al. (2001) Phenomenological two-gap model for the specific heat of $\mathrm{MgB}_{2}$. Europhys Lett 56: 856.

30. Ohishi K, Muranaka T, Akimitsu J, Koda A, Higemoto W, et al. (2003) Quasiparticle Excitations outside the Vortex Cores in $\mathrm{MgB}_{2}$ Probed by Muon Spin Rotation. J Phys Soc Jpn 72: 29-32.

31. Chen J, Salamon MB, Akutagawa S, Akimitsu J, Singleton J, et al. (2011) Evidence of nodal gap structure in the noncentrosymmetric superconductor $\mathrm{Y}_{2} \mathrm{C}_{3}$. Phys Rev B 83: 144529.

32. Potočnik A, Jeglič $P$, Kobayashi $K$, Kawashima $K$, Kuchida $S$, et al (2014) Anomalous local spin susceptibilities in noncentrosymmetric $\mathrm{La}_{2} \mathrm{C}_{3}$ superconductor. Phys Rev B 90: 104507.

33. Takano Y (2006) Overview. Sci Technol Adv Mater 7: S1

34. Takano Y, Takenouchi T, Ishii S, Ueda S, Okutsu S, et al. (2007) Superconducting properties of homoepitaxial CVD diamond. Diam Relat Mater 16: 911-914.

35. Bustarret E, Marcenat C, Achatz P, Kačmarčik J, Lévy F, et al. (2006) Superconductivity in doped cubic silicon. Nature 444: 465-468.

36. Sidorov VA, Ekimov EA, Stishov SM, Bauer ED, Thompson JT (2005) Superconducting and normal-state properties of heavily hole-doped diamond. Phys Rev B 71: 060502.

37. Dubrovinskaia N, Dubrovinsky L, Papageorgiou T, Bosak A, Krisch M, et al. (2008) Large carbon-isotope shift of TC in boron-doped diamond. Appl Phys Lett 92: 132506.

38. Yokoya T, Nakamura T, Matsushita T, Muro T, Takano Y, et al. (2005) Origin of the metallic properties of heavily boron-doped superconducting diamond. Nature 438: 647-650. 
39. Baskaran G (2008) Resonating Valence Bond Mechanism of Impurity Band Superconductivity in Diamond. J Supercond Nov Magn 21: 45-49.

40. Boeri L, Kortus J, Anderson OK (2004) Three-Dimensional MgB -Type $^{-}$ Superconductivity in Hole-Doped Diamond. Phys Rev Lett 93: 237002.

41. Lee KW, Pickett WE (2004) Superconductivity in Boron-Doped Diamond. Phys Rev Lett 9: 237003.

42. Lee KW, Pickett WE (2006) Boron spectral density and disorder broadening in B-doped diamond. Phys Rev B 73: 075105.

43. Blasé X, Adessi C, Connétable D (2004) Role of the dopant in the superconductivity of diamond. Phys Rev Lett 93: 237004.

44. Dan W, Ma YC, Wang ZL, Luo Q, Gu CZ, et al. (2006) Optical properties of boron-doped diamond. Phys Rev B 73: 012501.

45. Nakamura J, Kabasawa E, Yamada N, Einaga Y, Saito D, et al. (2004) Electronic structures of B2p and C2p levels in boron-doped diamond films studied using soft x-ray absorption and emission spectroscopy. Phys Rev B 70: 245111.

46. Nakamura J, Yamada N, Kuroki K, Oguchi T, Okada K, et al. (2008) Holes in the Valence Band of Superconducting Boron-Doped Diamond Film Studied by Soft X-ray Absorption and Emission Spectroscopy. J Phys Soc Jpn 77: 054711.

47. Mukuda H, Tsuchida T, Harada A, Kitaoka Y, Takenouchi T, et al. (2006) NMR study in boron-doped diamond films. Sci Techn Adv Mater 7: S37-S40.

48. Fukuyama $H$ (2006) High-Temperature Superconductivity by Transforming Bonds into Bands. J Supercond Nov Magn 19: 201-202.

49. Shirakawa T, Horiuchi S, Ohta Y, Fukuyama H (2007) Theoretical Study on Superconductivity in Boron-Doped Diamond. J Phys Soc Jpn 76: 014711.

50. Ohta Y, Shirakawa T, Horiuchi S, Fukuyama H (2007) B-doped diamond: Superconductivity without Fermi surface. Physica C: Superconductivity and its applications 460: 121-124.

51. Goldberg Y, Levinshtein ME, Rumyantsev SL (2001) Properties of Advanced Semiconductor Materials GaN, AIN, SiC, BN, SiC, SiGe. Levinshtein ME, Rumyantsev SL, Shur MS (Eds.) John Wiley \& Sons, Inc., New York, USA Pp: 93-148.

52. Hein RA, Gibson JW, Mazelsky R, Miller RC, Hulm JK (1964) Superconductivity in Germanium Telluride. Phys Rev Lett 12: 320.

53. Schooley JF, Hosler WR, Ambler E, Becker JH, Cohen ML (1965) Dependence of the Superconducting Transition Temperature on Carrier Concentration in Semiconducting $\mathrm{SrTiO}_{3}$. Phys Rev Lett 14: 305.

54. Lasbley A, Granger R, Rolland S (1973) High temperature superconducting behaviour in PbTe-Pb system. Solid State Comm 13: 1045-1048.

55. Kang JH, Maps J, Berkley DD, Jaeger HM, Goldman AM (1987) Superconducting transition in thin films of lead telluride doped with thallium. Phys Rev B 36: 2280.
56. Gurevich VL, Larkin AI, Firsov YA (1962) Possibility of superconductivity in semiconductors. Sov Phys Solid State 4: 185.

57. Cohen ML (1964) The Existence of a Superconducting State in Semiconductors. Rev Mod Phys 36: 240.

58. Silva AFD, Pernot J, Contreras S, Sernelius BE, Persson C, et al. (2006) Electrical resistivity and metal-nonmetal transition in n-type doped $4 \mathrm{H}-\mathrm{SiC}$ Phys Rev B 74: 245201.

59. Muranaka T, Kikuchi Y, Yoshizawa T, Shirakawa N, Akimitsu J (2008) Superconductivity in carrier-doped silicon carbide. Sci Technol Adv Mater 9: 044204

60. Achatz P, Pernot J, Marcenat C, Kacmarcik J, Ferro G, et al. (2008) Dopinginduced metal-insulator transition in aluminum-doped $4 \mathrm{H}$ silicon carbide. App Phys Lett 92: 072103.

61. Bracht H, Stolwijk NA, Laube M, Pensl G (2002) Diffusion of boron in silicon carbide: Evidence for the kick-out mechanism. Appl Phys Lett 77: 3188.

62. Rurali R, Godignon P, Rebollo J, Ordejon P, Hernandez E (2002) Theoretical evidence for the kick-out mechanism for B diffusion in SiC. Appl Phys Lett 81: 2989.

63. Gaoa Y, Soloviev SI, Sudarshan TS (2003) Investigation of boron diffusion in 6H-SiC. Appl Phys Lett 83: 905.

64. Gao F, William WJ, Posselt M, Belko V (2004) Atomistic study of intrinsic defect migration in 3C-SiC. Phys Rev B 69: 245205.

65. Fink HJ, McLachlan DS, Rothberg-Bibby B (1978) Progress in Low Temperature Physics. Brewer DF (Editor) (North-Holland, Amsterdam) VII B, Chap. 6.

66. Yonezawa S, Maeno $Y(2005)$ Type-I superconductivity of the layered silver oxide $\mathrm{Ag}_{5} \mathrm{~Pb}_{2} \mathrm{O}_{6}$. Phys Rev B 72: 180504.

67. Kriener M, Maeno Y, Oguchi T, Ren ZA, Kato J, et al. (2008) Specific heat and electronic states of superconducting boron-doped silicon carbide. Phys Rev B 78: 024517.

68. Kriener M, Muranaka T, Ren ZA, Kato J, Akimitsu J, et al. (2009) Superconductivity of hexagonal heavily-boron doped silicon carbide. J Phys Conf Ser 150: 052130.

69. Feder J (1967) Comments of the supercooling field for superconductors with $\mathrm{K}$ values near 0.4. Solid State Comm 5: 299-301.

70. Marchenko VI, Podolyak ER (2003) Phase diagram of surface superconductivity Sov Phys JETP 97: 154-161.

71. Drozdov AP, Eremets MI, Troyan IA, Ksenofontov V, Shylin SI (2015) Conventional superconductivity at 203 kelvin at high pressures in the sulfur hydride system. Nature 525: 73-76. 